\title{
Genetic modifiers of the BRD4-NUT dependency of NUT midline carcinoma uncovers a synergism between BETis and CDK4/6is
}

\author{
Sida Liao, ${ }^{1,2}$ Ophélia Maertens, ${ }^{1,3,4}$ Karen Cichowski, ${ }^{1,3,4}$ and Stephen J. Elledge ${ }^{1,2,4}$ \\ ${ }^{1}$ Division of Genetics, Department of Medicine, Brigham and Women's Hospital, Boston, Massachusetts 02115, USA; ${ }^{2}$ Department \\ of Genetics, Program in Virology, Howard Hughes Medical Institute, Harvard Medical School, Boston, Massachusetts 02115, USA; \\ ${ }^{3}$ Harvard Medical School, Boston, Massachusetts 02115, USA; ${ }^{4}$ Ludwig Center at Harvard, Harvard Medical School, Boston, \\ Massachusetts 02215, USA
}

Bromodomain and extraterminal (BET) domain inhibitors (BETis) show efficacy on NUT midline carcinoma (NMC). However, not all NMC patients respond, and responders eventually develop resistance and relapse. Using CRISPR and ORF expression screens, we systematically examined the ability of cancer drivers to mediate resistance of NMC to BETis and uncovered six general classes/pathways mediating resistance. Among these, we showed that RRAS2 attenuated the effect of JQ1 in part by sustaining ERK pathway function during BRD4 inhibition. Furthermore, overexpression of Kruppel-like factor 4 (KLF4), mediated BETi resistance in NMC cells through restoration of the E2F and MYC gene expression program. Finally, we found that expression of cyclin D1 or an oncogenic cyclin D3 mutant or RB1 loss protected NMC cells from BETi-induced cell cycle arrest. Consistent with these findings, cyclindependent kinase 4/6 (CDK4/6) inhibitors showed synergistic effects with BETis on NMC in vitro as well as in vivo, thereby establishing a potential two-drug therapy for NMC.

[Keywords: BETi; BRD4; CDK4; genetic screens; JQ1; oncogenes; tumor suppressor]

Supplemental material is available for this article.

Received April 12, 2018; revised version accepted July 17, 2018.

NUT midline carcinoma (NMC) is an aggressive subtype of squamous cell cancer. Genetically, it is defined by the fusion of most of the coding sequence of the testesspecific gene NUT on chromosome 15 to several other genes-most frequently the BRD4 gene on chromosome 19 (BRD4-NUT) (French et al. 2003, 2008). BRD4 is an epigenetic reader that binds to acetyl-histone. Fusion to the NUT protein results in recruitment of p300/CBP, a histone acetyltransferase, leading to regional histone hyperacetylation. Such acetylation further recruits BRD4-NUT in a feed-forward manner, eventually creating massive regions of acetylated chromatin that covers individual topologically associated domains across the genome (Alekseyenko et al. 2015). The transcription of oncogenic proteins such as c-Myc (encoded by MYC) and its regulators within these regions is thus stimulated, blocking cellular differentiation and promoting uncontrolled growth of carcinoma cells (Grayson et al. 2014; Alekseyenko et al. 2015).

Small molecule bromodomain and extraterminal (BET) domain inhibitors (BETis) that target and inhibit BRD4's

Corresponding author: selledge@genetics.med.harvard.edu Article published online ahead of print. Article and publication date are online at http://www.genesdev.org/cgi/doi/10.1101/gad.315648.118. association with chromatin have shown anti-cancer efficacy on a variety of cancers, including NMC, in preclinical models and are currently being evaluated in clinical trials (Stathis and Bertoni 2018). A clinical proof of concept for BETis in NMC was demonstrated recently (Stathis et al. 2016). Two of four NMC patients receiving BRD4 inhibition therapy showed increased overall survival (19 and $18 \mathrm{mo}$, respectively), which was notably longer than the median survival of 6.7 mo reported in the largest retrospective series of patients with NMC (Bauer et al. 2012). However, as is often the case with other single-agent therapies, cancer cells can develop resistance to BETis through a variety of mechanisms (De Raedt et al. 2014; Fong et al. 2015; Kumar et al. 2015; Hogg et al. 2016; Kurimchak et al. 2016; Marcotte et al. 2016; Shi et al. 2016; Shu et al. 2016; Jang et al. 2017; Janouskova et al. 2017). Despite the initial response, all of the NMC patients developed resistance to the BETis and eventually

(C) 2018 Liao et al. This article is distributed exclusively by Cold Spring Harbor Laboratory Press for the first six months after the full-issue publication date (see http://genesdev.cshlp.org/site/misc/terms.xhtml). After six months, it is available under a Creative Commons License (Attribution-NonCommercial 4.0 International), as described at http://creativecommons.org/licenses/by-nc/4.0/. 
relapsed. Therefore, there is an urgent need to identify the underlying mechanisms of resistance to BRD4 inhibition in NMC in order to develop combination therapies or alternative regimens after BRD4 inhibitor progression.

Cancer is driven by a number of distinct genetic alterations, including gain or loss of chromosomes and chromosomal segments, translocations, frameshifts, and point mutations that result in inactivation of tumor suppressor genes (TSGs) or activation of oncogenes. We previously developed an algorithm called TUSON Explorer to identify known and putative cancer drivers using human tumor sequencing data (Davoli et al. 2013). This method quantifies the likelihood that a gene is a cancer driver based on the distortion of its mutational signature from the pattern expected for a "neutral" gene. For example, TSGs will have a higher ratio of loss-of-function to benign mutations than neutral genes, while oncogenes will have a higher ratio of missense to benign mutations than neutral genes, and these missense mutations tend to cluster together (Fig. 1A). We and others have shown that cancer drivers can genetically interact and substitute for one another to drive proliferation and survival in EGFR mutant nonsmall cell lung cancers and other cancer models (Harbinski et al. 2012; Wilson et al. 2012; Sharifnia et al. 2014; Liao et al. 2017), suggesting that it might be a general notion that cancer drivers can form a function network and genetically modify the dependency of each other. Thus, the TSGs and oncogenes identified by TUSON Explorer could serve as an ideal list to survey for the genetic modifiers that can partially replace the cancer driver of interest-BRD4-NUT, in the case of NMC.

To systematically identify the TSGs and oncogenes that can partially replace BRD4-NUT in BRD4-NUT-dependent NMC tumor cells, we performed CRISPR and oncogene/proto-oncogene expression screens in parallel using an in vitro NMC model. Here, we show that this genetic approach successfully recovered previously validated cancer drivers that mediate BETi resistance, such as $M Y C$, in addition to novel cancer drivers not previously linked to BETi resistance in NMC. We further characterized the mechanisms underlying BETi resistance mediated by several novel oncogenes. Among these, we showed that mutation of RRAS2, a member of the R-Ras subfamily of Raslike small GTPases, attenuated the effect of JQ1 in part by sustaining ERK pathway function during BRD4 inhibition. We also showed that overexpression of Kruppellike factor $4(K L F 4)$, a transcriptional factor, mediated JQ1 resistance in NMC cells through restoring the E2F and MYC gene expression program upon JQ1 treatment. Finally, we showed that expression of cyclin D1 and mutant cyclin D3 or loss of $R B 1$ protected the NMC cells from JQ1-induced cell cycle arrest. In accordance with this observation, cyclin-dependent kinase $4 / 6$ (CDK4/6) inhibitors showed synergistic effects with JQ1 on NMC in vitro as well as in vivo, revealing the central role of cell cycle regulation in mediating JQ1 response. These
A

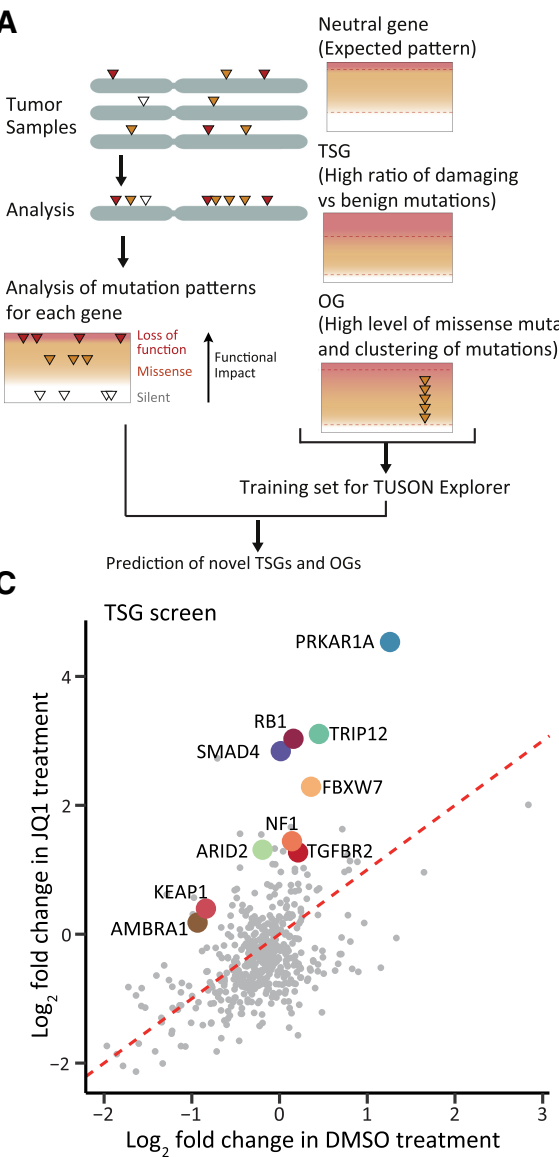

B

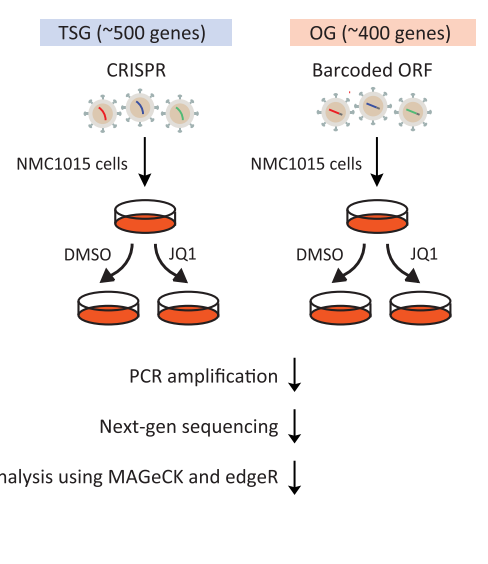

D

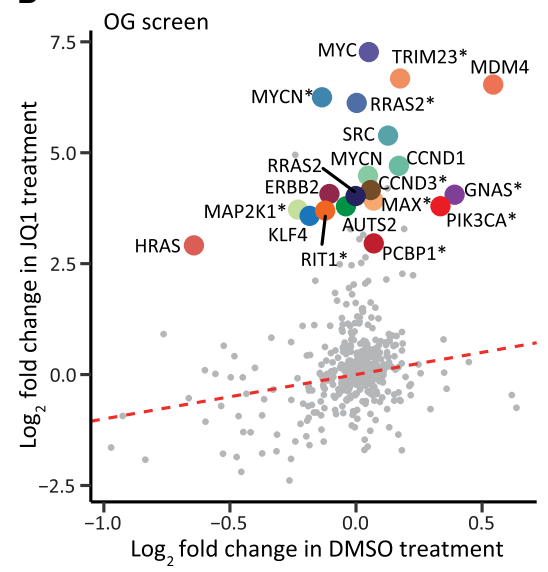

Figure 1. Genetic screens identify modifiers of the cellular response to reduced BRD4-NUT signaling. $(A)$ Schematic of the pipeline used by TUSON Explorer to predict TSGs and oncogenes (OGs). (B) Outline of the genetic screening strategy. $(C, D) \log _{2}$ fold change comparing end time point (day 17) with start time point (day 0) of JQ1 treatment plotted against vehicle (DMSO) treatment for genes in the CRISPR and ORF screens, respectively. The top 10 genes of the CRISPR screen and the top 20 genes of the ORF screen (false discovery rate [FDR] $<0.05)$ are highlighted. The asterisk indicates a mutant form of the gene. 
findings provide new biochemical insight into the resistance mechanisms to BETis in NMC as well as a rationale for combination therapy of BETis and CDK4/6 inhibition on NMC.

\section{Results}

To investigate the question of which drivers could substitute for BRD4-NUT in NMC, we used a CRISPR library containing 10 guide RNAs (gRNAs) per gene to a list of $\sim 500$ putative TSGs implicated using the TUSON Explorer algorithm (Fig. 1A). In addition, we expanded a doxycycline (Dox)-inducible barcoded ORF library of putative oncogenes (Liao et al. 2017) to a total of $\sim 400$ constructs that contained $\sim 150$ both wild-type proto-oncogenes and their recurring mutant alleles identified by TUSON. We also included genes that are frequently amplified in cancers (Santarius et al. 2010), identified in the Cancer Gene Census (Futreal et al. 2004), or implicated in cancer hallmarks such as cell proliferation (Sack et al. 2018), anchorage-independent growth (Pavlova et al. 2013), epithelial-to-mesenchymal transition (Taube et al. 2010), etc. as well as 40 "neutral genes" that behaved in a neutral fashion in a previous genetic screen that looked for cell proliferation regulators (Sack et al. 2018). We used these libraries to determine which alterations could substitute for BRD4-NUT signaling using a chemical inhibitor of BRD4: JQ1. We performed screens using a NMC cell line (NMC1015) that harbors a BRD4-NUT fusion and is sensitive to JQ1 (Grayson et al. 2014).

The schematic of the CRISPR and ORF screens is outlined in Figure 1B and described in detail in the Supplemental Material. In each screen, cells were treated with either DMSO or $200 \mathrm{nM}$ JQ1 for $\sim 17 \mathrm{~d}$. We used the MAGeCK (model-based analysis of genome-wide CRISPR/Cas9 knockout) scoring algorithm (Li et al. 2014) and edgeR analysis (Robinson et al. 2010) to rank the performance of individual genes in the CRISPR and ORF screen, respectively, based on enrichment, comparing the JQ1 treatment group with the DMSO treatment group. The rank and false discovery rate (FDR) of each gene in the two screens are summarized in Supplemental Table S1. The top 10 hits $(F D R<0.05)$ from the CRISPR screen and top 20 hits $(F D R<0.05)$ from the ORF screen are shown in Figure 1, C and D. An immediate validation of our screen approach is that $M Y C$, a major downstream target of BRD4-NUT that can replace its function to prevent differentiation/arrested proliferation induced by the knockdown of BRD4-NUT (Grayson et al. 2014), scored as the number one hit in the oncogene screen.

Notably, the novel cancer drivers that we identified largely fall into the following five categories: (1) MYC-related genes: $M Y C N$ (wild type and c.131C > T; p.P44L), $M A X$ (c.179G > A; p.R60Q), and FBXW7; (2) the receptor tyrosine kinase (RTK) signaling pathway: ERBB2, $S R C$, RRAS2 (wild type and c.216A > C; p.Q72H), H-RAS, Neurofibromatosis type 1 (NF1), MAP2K1 (c.371C > A; p.P124Q), and PIK3CA (c.3140A > G; p.H1047R); (3) cell cycle regulation: CCND1, CCND3 (c.869T > G; p.I290R), and $R B 1 ;(4)$ the G-protein-coupled receptor (GPCR)/cyclic AMP (cAMP)/cAMP-dependent protein kinase A (PKA) signaling pathway: GNAS (c.2530C > T; p.R844C) and PRKAR1A; and (5) the transforming growth factor $\beta$ (TGF- $\beta$ ) pathway: SMAD4 and TGFBR2.

Given the stronger phenotype (larger fold change) induced by the oncogenes compared with TSGs, we primarily focused our efforts on characterization of the novel oncogene hits.

Mutant RRAS2 attenuates the effect of JQ1 by sustaining ERK pathway activation during BRD4-NUT inhibition

One of the top hits identified in our oncogene screen is $R R A S 2$, a Ras-related GTPase with transforming potential (Chan et al. 1994; Graham et al. 1994). Downstream effectors of RRAS2 include three members of the mitogen-activated protein kinases (MAPKs); namely, ERK1/2, c-Jun N-terminal kinase, and p38 MAPK as well as phosphoinositide 3-kinase (PI3K) (Graham et al. 1994; Movilla et al. 1999; Rosario et al. 2001; Murphy et al. 2002). The amino acid Q72 of RRAS2 is conserved in K-Ras, H-Ras, and NRas (Q61) in humans (Fig. 2A). Q61 mutations in KRAS are commonly found in human cancers, and mutations such as Q61L have been shown to increase KRAS activity through higher affinity to RAF kinase compared with wild type (Hunter et al. 2015). Consistent with this, both wildtype and Q72H mutant RRAS2 scored in our screen, and the mutant form showed a stronger phenotype (larger fold change) in the screen (Fig. 1D).

To explore how RRAS2 impacts JQ1 resistance in NMC cells, we first validated the effect of expression of Q72H mutant RRAS2 on JQ1 resistance using an independent NMC cell line, NMC797 cells (Toretsky et al. 2003). As seen with NMC1015 cells, expression of mutant RRAS2 significantly increased the survival of NMC797 cells in response to JQ1 treatment, as measured by sulforhodamine $\mathrm{B}$ (SRB) assay (Fig. 2B). To identify the downstream effectors of mutant RRAS2, we examined the two signaling kinases that have been reported previously to be responsible for RRAS2-induced cell transformation: ERK and PI3K.

Surprisingly, JQ1 treatment inhibited ERK signaling measured by ERK1/2 phosphorylation (p-ERK1/2) and phosphorylation of its downstream effector, P90RSK (pP90RSK), starting as early as $6 \mathrm{~h}$ and reduced the phosphorylation of those two proteins to nearly undetectable levels by $24 \mathrm{~h}$ in NMC1015 cells (Fig. 2C). However, expression of RRAS2 ${ }^{\mathrm{Q} 72 \mathrm{H}}$ abolished the effect of JQ1 on ERK signaling (Fig. 2C). JQ1 also decreased the phosphorylation of AKT (p-AKT) and phosphorylation of its downstream effector, PRAS40 (p-PRAS40), at $6 \mathrm{~h}$, and phosphorylation was barely detectable at $24 \mathrm{~h}$ (Fig. 2C). Expression of RRAS2 ${ }^{\mathrm{Q} 72 \mathrm{H}}$ activated AKT and restored PRAS40 phosphorylation in the presence of JQ1, demonstrating that RRAS2 ${ }^{\mathrm{Q72H}}$ can rescue both of these signaling arms.

We note that JQ1 reduced the protein level of c-Myc (a known JQ1 target) and cyclin D1 (another gene identified in our screen in NMC1015 cells) with kinetics similar to its effect on ERK and AKT signaling. Cells expressing mutant RRAS2 also showed higher levels of c-Myc and 
A

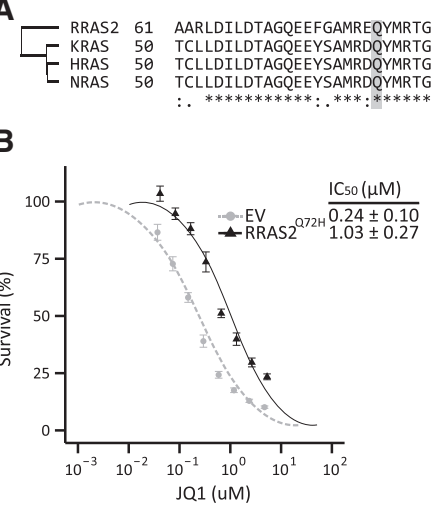

D

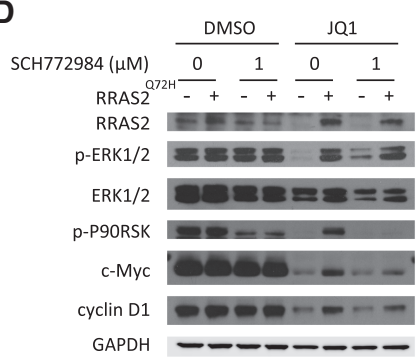

C

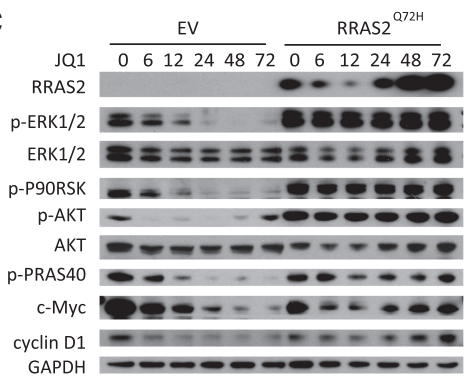

E

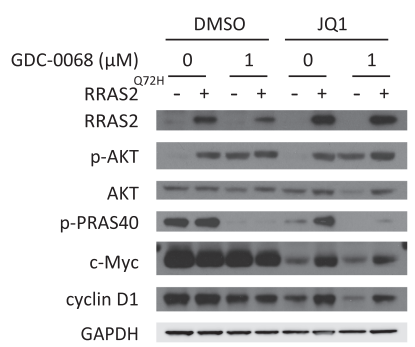

$\mathbf{F}$

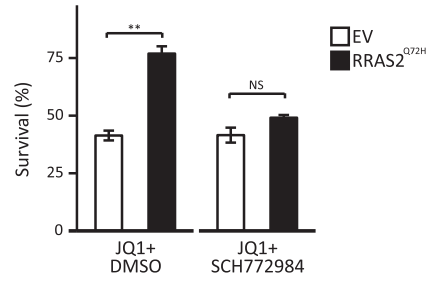

Figure 2. Mutant RRAS2 attenuates the effect of JQ1 by sustaining ERK pathway activation during BRD4-NUT inhibition. (A) Protein sequence alignment of human RRAS2 (UniProt entry P62070), KRAS (UniProt entry P01116), HRAS (UniProt entry P01112), and NRAS (UniProt entry P01111) using UniProt. An asterisk indicates positions that have a single fully conserved residue. A colon (:) indicates conservation between groups of strongly similar properties (roughly equivalent to scoring $>0.5$ in the Gonnet PAM 250 matrix). A single dot indicates conservation between groups of weakly similar properties (roughly equivalent to scoring between 0 and 0.5 in the Gonnet PAM 250 matrix). (B) NMC797 cells containing an empty vector $(\mathrm{EV})$ or expressing the RRAS2 ${ }^{\mathrm{Q} 72 \mathrm{H}} \mathrm{mu}-$ tant were treated with the indicated concentrations of JQ1 for $72 \mathrm{~h}$ before cell viability was measured using a sulforhodamine $B(S R B)$ assay and normalized to untreated controls. Data are means \pm SD. $n=3$. $(C)$ Immunoblot analysis of NMC1015 cells containing an empty vector (EV) or expressing the RRAS2 ${ }^{\mathrm{Q72H}}$ mutant treated with $200 \mathrm{nM}$ JQ1 for the indicated time period and probed with the indicated antibodies. $(D)$ Immunoblot analysis of NMC1015 cells containing an empty vector (EV) or expressing the RRAS2 ${ }^{\mathrm{Q} 72 \mathrm{H}}$ mutant treated with DMSO or $200 \mathrm{nM}$ JQ1 and the indicated concentrations of SCH772984 for $72 \mathrm{~h}$ and probed with the indicated antibodies. (E) Immunoblot analysis of NMC1015 cells containing an empty vector (EV) or expressing the RRAS2 ${ }^{\mathrm{Q} 72 \mathrm{H}}$ mutant treated with DMSO or $200 \mathrm{nM}$ JQ1 and the indicated concentrations of GDC-0068 for $72 \mathrm{~h}$ and probed with the indicated antibodies. $(F)$ NMC1015 cells containing an empty vector (EV) or expressing the RRAS2 ${ }^{\mathrm{Q} 72 \mathrm{H}}$ were treated with $200 \mathrm{nM}$ JQ1 plus DMSO or $1 \mu \mathrm{M}$ SCH772984 for $72 \mathrm{~h}$ before cell viability was measured using an SRB assay. Results were normalized to untreated controls. Data are means \pm SD . $\left.n=3 .{ }^{* *}\right) P<0.01$; (NS) not significant. cyclin D1, providing an attractive mechanism of action (Fig. 2C). Because ERK and AKT can regulate both of these pathways, we investigated their contributions to c-Myc and cyclin D1 expression downstream from RRAS2. Cells were cotreated with JQ1 and an ERK inhibitor (SCH772984) or an AKT inhibitor (GDC-0068). As noted above, JQ1 suppressed p-ERK and p-P90RSK and dramatically reduced the expression of c-Myc and cyclin D1, whereas RRAS2 largely restored ERK and P9ORSK phosphorylation and increased c-Myc and cyclin D1 expression levels. Notably, SCH772984 reversed the effects of RRAS2 on p-ERK and p-P90RSK (Fig. 2D). Interestingly, the higher levels of c-Myc and cyclin D1 in mutant RRAS2-expressing NMC1015 cells during JQ1 treatment were also reduced to that of control cells by SCH772984 treatment. SCH772984 did not further reduce the pP90RSK level of control NMC1015 cells, suggesting that JQ1 alone potently inhibited ERK signaling in these cells.

As expected, GDC-0068 reduced p-PRAS40 levels of mutant RRAS2-expressing cells to that of control cells treated with JQ1 alone. However, it had less of an effect on c-Myc and cyclin D1 in mutant RRAS2-expressing cells than the ERK inhibitor (Fig. 2E). Together, these results suggest that the RRAS2 mutant attenuates the sup- pressive effect of JQ1 on c-Myc and cyclin D1 levels, primarily through sustained ERK signaling, although sustained AKT may also contribute to a lesser extent.

The observation that ERK inhibitors could effectively reverse the effects of RRAS2 on these important downstream signals in JQ1-treated cells suggested that ERK inhibitors might also negate the resistance conferred by RRAS2 in JQ1-treated cells. Consistent with signaling changes, while SCH772984 did not further reduce the viability of JQ1-treated control cells, SCH772984 resensitized mutant RRAS2-expressing cells to JQ1 (Fig. 2F). The contribution of ERK signaling to JQ1 resistance is further supported by the fact that the upstream kinase of ERK1/2, MEK1 (encoded by MAP2K1), also scored highly in the oncogene screen (Fig. 1D). Thus, sustained ERK signaling significantly contributes to the ability of RRAS2 to overcome JQ1's effect on survival.

\section{KLF4 mediated JQ1 resistance in NMC cells through restoring the E2F and MYC gene expression program upon JQ1 treatment}

Another novel hit identified in our oncogene screen is the Yamanaka factor KLF4. KLF4 is a zinc finger-containing 
transcription factor that plays a critical role in regulating a variety of cellular processes such as proliferation, differentiation, development, maintenance of normal tissue homeostasis, and apoptosis. It can function as a TSG or oncogene in different cancers, depending on the cellular context (Rowland and Peeper 2006). As an oncogene, KLF4 has been shown to mediate resistance to a variety of therapies such as chemotherapy and Her2 inhibition (Farrugia et al. 2015; Lund et al. 2017). However, how it might modulate BRD4-NUT dependency is unclear.

We first validated the effect of KLF4 expression on JQ1 resistance in NMC cells using a 3-d SRB assay. Surprisingly, expression of KLF4 did not provide NMC cells with resistance to JQ1 as measured by this short-term viability assay (Supplemental Fig. S1A,B). However, when we examined the effect of KLF4 expression on JQ1 resistance using a longer-term colony formation assay, which is more reflective of the initial screen, KLF4 expression significantly enhanced the colony formation of NMC1015 cells in the presence of JQ1 (Fig. 3A). One possible explanation is that KLF4 may take substantial time to remodel the cell state like Yamanaka factors have been suggested to work (Polo et al. 2012). Therefore, we pretreated KLF4infected NMC797 and NMC1015 cells with Dox for 4 wk and measured their sensitivity to JQ1 using the 3-d SRB assay. Again, KLF4-expressing NMC cells did not show differential sensitivity to JQ1 (data not shown), suggesting that it is not the length of time of KLF4 expression but the length of time of JQ1 exposure that determines the ability of KLF4-expressing cells to mediate JQ1 resistance.

To identify the effectors that are induced by KLF4 in the JQ1 resistance setting, we performed RNA sequencing (RNA-seq) on empty vector or KLF4-expressing NMC1015 cells. Cells were treated with DMSO or 200 nM JQ1 for $6 \mathrm{~h}, 24 \mathrm{~h}$, or $7 \mathrm{~d}$ (Fig. 3B). The full analyses of differentially expressed genes (DEGs) across different conditions are shown in Supplemental Table S2. Among the top genes that are differentially expressed comparing KLF4-expressing and control cells under JQ1 treatment, $M Y C$; its downstream target, TERT; and several long noncoding RNAs (lncRNAs) such as CCAT1 and CASC19 stood out (Fig. 3C). Notably, the transcriptional down-regulation of those genes by JQ1 is attenuated by KLF4 expression only at late ( $7 \mathrm{~d}$ ) but not early (6 and $24 \mathrm{~h}$ ) time points, which is consistent with the observation that KLF4-expressing cells manifest a resistant phenotype only in long-term, but not short-term, survival assays.

CCAT1 and CASC19 are near the MYC locus, and CCAT1 has been reported to play oncogenic roles through transcriptional up-regulation of MYC (Xiang et al. 2014; McCleland et al. 2016). Previously, Alekseyenko et al. (2015) had shown that CCAT1 and CASC19 are among the few genes that are within BRD4-NUT megadomains

\section{A}

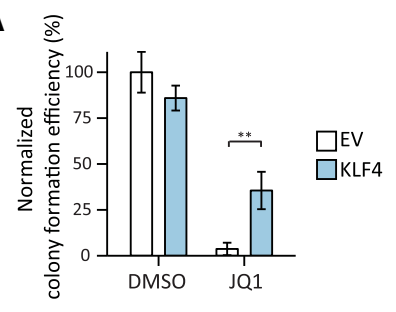

B

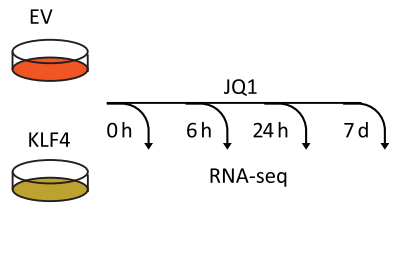

C

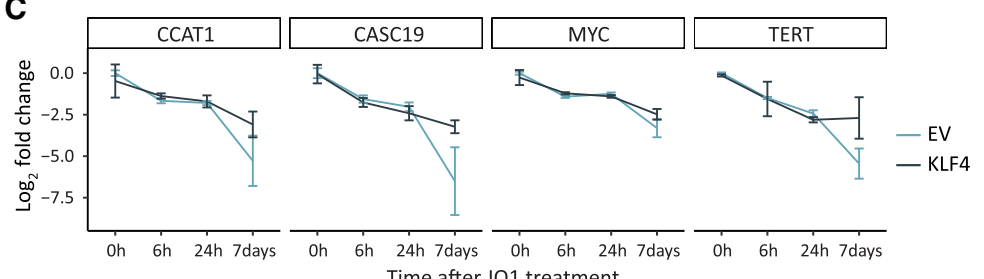

D

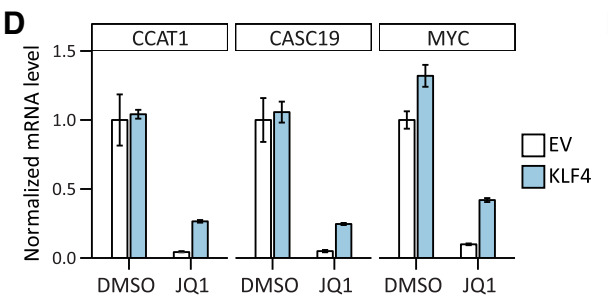

$\mathbf{F}$
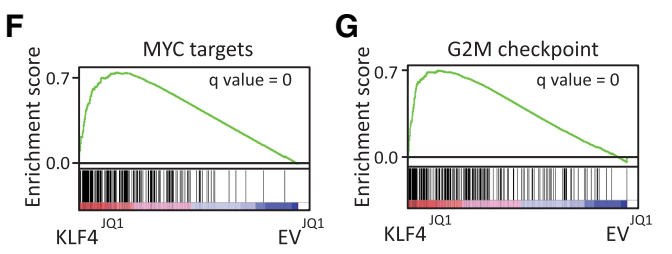

E
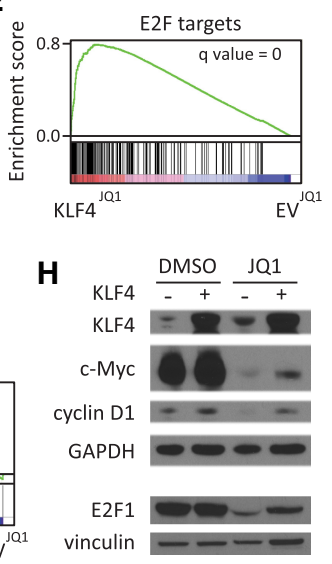

Figure 3. KLF4 mediated JQ1 resistance in NMC cells through restoring the E2F and MYC gene expression program upon JQ1 treatment. (A) KLF4 expression enhances survival of NMC1015 cells in long-term colony formation assays with JQ1. NMC1015 cells containing control (EV) or KLF4 expression vectors were fixed and stained after treatment with DMSO for $1 \mathrm{wk}$ or $200 \mathrm{nM}$ JQ1 for $6 \mathrm{wk}$. Colony numbers of each condition were quantified using ImageJ and normalized to control cells under DMSO treatment. Data are means \pm SD. $n=3$. $\left({ }^{* *}\right) P<$ 0.01 . $(B)$ Schematic of the time course for the RNA sequencing (RNA-seq) experiment. NMC1015 cells containing control (EV) or KLF4 expression vectors were treated with $200 \mathrm{nM}$ JQ1 for the indicated times. Differentially expressed genes (DEGs) were identified using edgeR. $(C) \log _{2}$ fold change of normalized gene expression level (counts per million) as measured using RNAseq of the indicated genes in NMC1015 cells containing control (EV) or KLF4 expression vectors treated with 200 $\mathrm{nM}$ JQ1 for the indicated times. Data are the means \pm SD. $n=2$. $(D)$ RT-qPCR analysis of mRNA expression of the indicated genes in NMC1015 cells containing control (EV) or KLF4 expression vectors treated with DMSO or $200 \mathrm{nM}$ JQ1 for $7 \mathrm{~d}$. Data are the means \pm SD. $n=3$. $(E-G)$ Gene set enrichment analysis plots. Plots indicate a significant up-regulation of E2F targets, MYC targets, and G2M checkpoint signatures in KLF4expressing NMC1015 cells compared with NMC1015 cells containing an empty vector (EV) during JQ1 treatment at day 7. $(H)$ Immunoblot analysis of NMC1015 cells containing control (EV) or KLF4 expression vectors treated with DMSO or $200 \mathrm{nM} \mathrm{JQ1}$ for $7 \mathrm{~d}$ and probed with the indicated antibodies. 
that overlap in multiple NMC cell lines, including NMC797 and NMC1015 cells, and whose expression is significantly reduced by JQ1 treatment. We validated the RNA-seq results using RT-qPCR (Fig. 3D). Our data indicate that expression of KLF4 prevents the down-regulation of CCAT1 and CASC19 by JQ1, which might result in higher MYC levels and thus resistance to JQ1. Indeed, gene set enrichment analysis (GSEA) revealed that E2F targets, MYC targets, and G2M checkpoint genes comprised the top-ranking gene sets when comparing the KLF4-expressing NMC1015 cells with control cells under JQ1 treatment at day 7 (Fig. 3E-G). In agreement with this, KLF4-expressing cells exhibited higher levels of E2F1, cMyc, and cyclin D1 during JQ1 treatment compared with control cells (Fig. 3H). Taken together, these data suggest that KLF4-expressing cells are able to sustain the MYC and E2F gene expression programs under JQ1 treatment and bypass the cell cycle arrest induced by JQ1, providing a second distinct mechanism of resistance involving these same pathways.

\section{The central role of cell cycle regulators in mediating JQ1 resistance}

One recurring theme from our screens is cell cycle regulation. $R B 1$ is a TSG that negatively regulates E2F-dependent transcription and cell cycle entry (Dyson 2016). During G1/S cell cycle progression, CDK4 and CDK6 form a complex with their regulatory subunit, D-type cyclins, which phosphorylates the $\mathrm{Rb}$ protein, resulting in its dissociation from E2F and activation of transcription of genes that are important for S phase, such as cyclin A (Schulze et al. 1995). Two central G1/S transition regulators-cyclin D1 and a mutant form of cyclin D3 (c.869T > G; p.I290R) that is highly stable (Schmitz et al. 2012)scored as top 10 hits in the oncogene screen. In addition, the downstream inactivation target of the CDK4/6-Cyclin D complex, the RB1 gene, scored in the top 10 of TSG screens, and $F B X W 7$, an F-box protein that targets cyclin E and c-Myc for degradation (Koepp et al. 2001; Welcker et al. 2004; Yada et al. 2004), also scored highly in the TSG screen, further implicating the cell cycle.

We first validated the effect of expression of cyclin D1 and mutant cyclin D3 on JQ1 resistance using an independent NMC cell line, NMC797 cells. As seen with the NMC1015 cells in the screen, expression of cyclin D1 or mutant cyclin D3 significantly increased the survival of NMC797 cells under JQ1 treatment (Fig. 4A,B). To validate that loss of $R B 1$ mediates JQ1 resistance, we used CRISPR to knock out RB1 in NMC797 cells. Cells expressing Cas9 and two independent gRNAs targeting $R B 1$ showed significantly increased survival in response to JQ1 compared with cells expressing Cas9 and control gRNAs targeting AAVS1 or GFP (Fig. 4C). Thus, these cell cycle regulators mediate JQ1 resistance in multiple NMC cell lines.

We next returned to the NMC1015 cells to explore how JQ1 affects the CDK4/6-cyclin D/Rb signaling axis by examining the levels of these proteins in NMC1015 cells. JQ1 treatment reduced cyclin D1 levels, Rb phosphoryla-
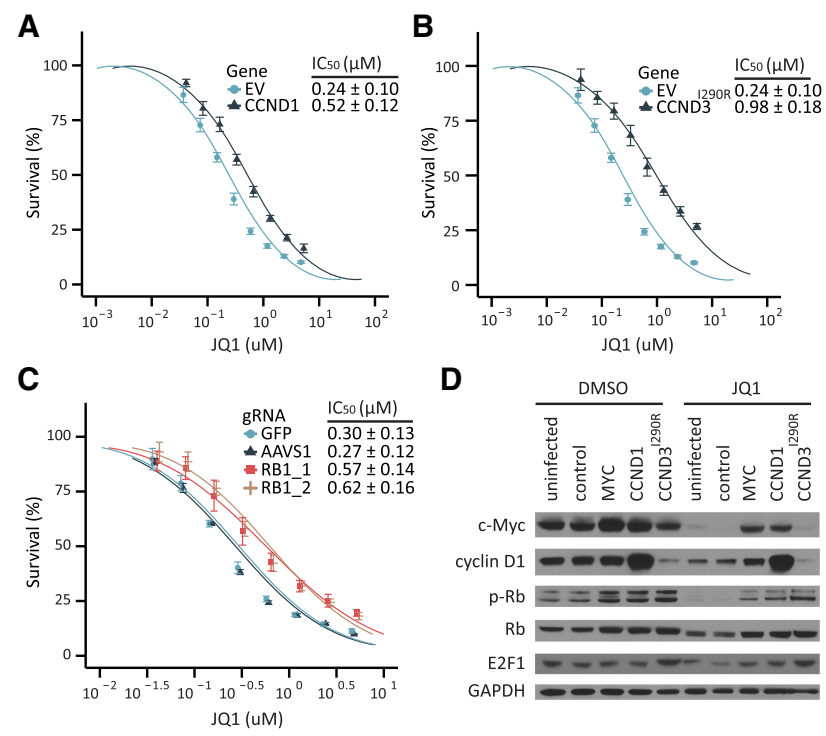

D

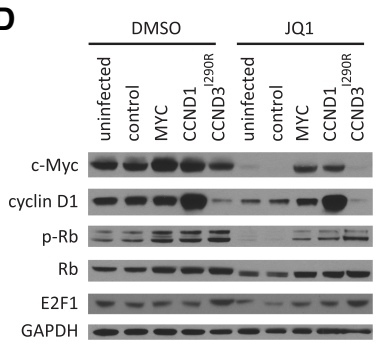

Figure 4. A central role for cell cycle regulators in mediating JQ1 resistance. $(A-C)$ NMC797 cells expressing the indicated genes or Cas 9 and gRNAs targeting the indicated genes were treated with the indicated concentrations of JQ1 for $72 \mathrm{~h}$ before cell viability was measured using an SRB assay and normalized to untreated controls. Data are means \pm SD. $n=3$. (D) Immunoblot analysis of NMC1015 cells expressing the indicted genes treated with DMSO or $200 \mathrm{nM}$ JQ1 for $24 \mathrm{~h}$ and probed with the indicated antibodies.

tion $(\mathrm{p}-\mathrm{Rb})$, and E2F1 levels in uninfected parental or control infected NMC1015 cells (Fig. 4D). Like MYC, ectopic expression of D-type cyclins restored $\mathrm{p}-\mathrm{Rb}$ and $\mathrm{E} 2 \mathrm{~F} 1$ levels in the presence of JQ1. Together, our data suggest that JQ1 down-regulates cyclin D1, whose reduction results in hypophosphorylation of $\mathrm{Rb}$ and cell cycle arrest. Blocking $\mathrm{Rb}$ activation by JQ1 through either RB1 loss or upregulation of cyclin D1 or D3 is sufficient to induce JQ1 resistance.

\section{The CDK4/6 inhibitor synergizes with JQ1 on NMC in vitro}

Given that c-Myc can activate expression of D-type cyclins and the ability of ectopic expression of D-type cyclins to mediate JQ1 resistance, we hypothesize that the endogenous CDK4/6-cyclin $\mathrm{D} / \mathrm{Rb}$ axis may play an important role in modulating JQ1 sensitivity and that CDK4/6 inhibition should synergize with JQ1. To test this hypothesis, we cotreated NMC1015 cells with JQ1 and the CDK4/6 inhibitor palbociclib and measured cell viability. We found that the combination of JQ1 and palbociclib achieved significantly higher cell proliferation inhibition than either drug alone across a range of doses (Fig. 5A). We observed such synergism also on NMC797 cells (Fig. 5B). To further quantify the synergistic effect between JQ1 and palbociclib and rule out the possibility of additive effect, we calculated the combination indices (CIs) of a range of different combinations of JQ1 and palbociclib on NMC1015 cells. A CI between 0 and 1 indicates a 

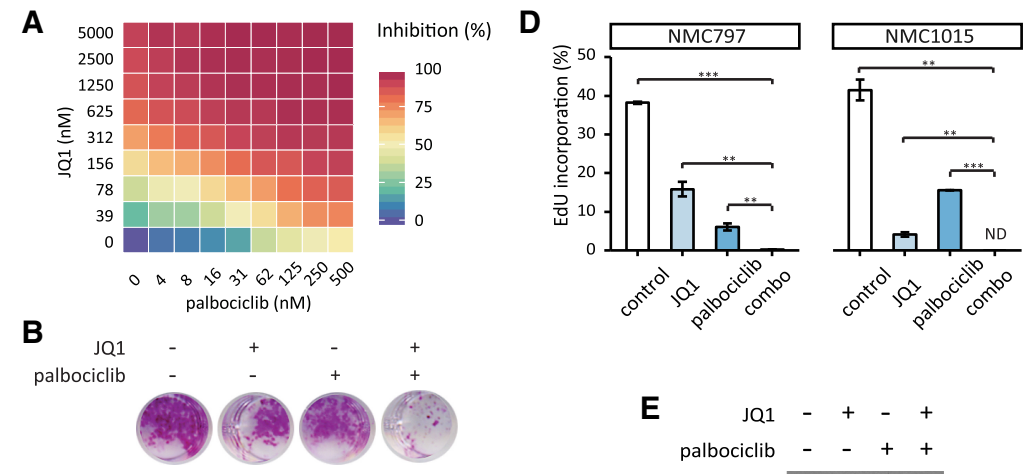

C
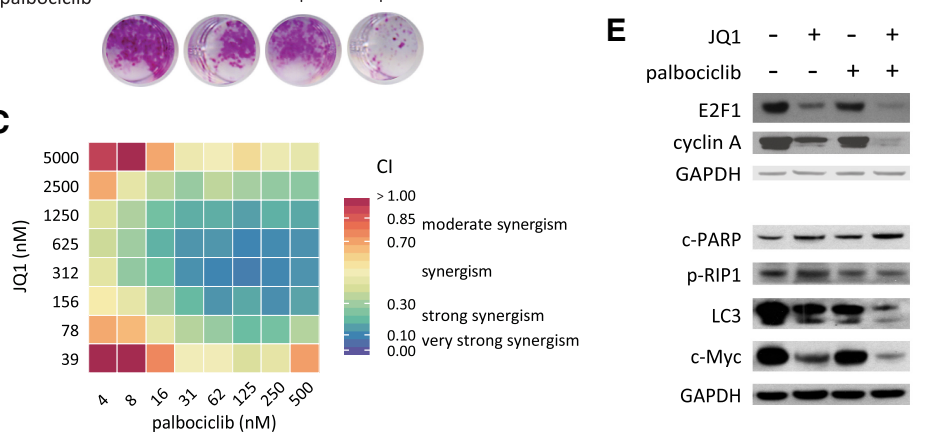

Figure 5. CDK4/6 inhibitors synergize with JQ1 to inhibit NMC growth in vitro. (A) NMC1015 cells were treated with the combination of the indicated concentrations of JQ1 and palbociclib for $72 \mathrm{~h}$ before cell viability and inhibition percentage were measured using an SRB assay and normalized to untreated controls. Data are means. $n=3$. $(B)$ Cell viability assays of NMC797 cells treated with either vehicle, $625 \mathrm{nM}$ JQ1, $250 \mathrm{nM}$ palbociclib, or the combination of both drugs for $72 \mathrm{~h}$. Cells were stained using SRB after treatment. (C) CI analysis of NMC1015 cells treated with the combination of the indicated doses of JQ1 and palbociclib for $72 \mathrm{~h}$ based on the viability inhibition percentage in $A$ using CalcuSyn. Data are means. $n=3$. (D) Cell cycle profiles of NMC797 and NMC1015 cells treated with either $200 \mathrm{nM}$ JQ1, $400 \mathrm{nM}$ palbociclib, the combination of both drugs, or vehicle (control) for 48 h. Incorporated EdU percentage is used to indicate the percentage of cells that went into cell cycle. Data are means \pm SD. $\left.n=3 .\left(^{* *}\right) P<0.01 ;\left.\right|^{* * *}\right) P<$ 0.001; (ND) not detected. (E) Immunoblot analysis of NMC1015 cells treated with either $200 \mathrm{nM}$ JQ1, $400 \mathrm{nM}$ palbociclib, the combination of both drugs, or vehicle for $48 \mathrm{~h}$. synergistic effect between two drugs, and the closer the index is to 0 , the stronger the synergism /Chou and Talalay 1984). We found that palbociclib showed strong synergism $(\mathrm{CI}<0.3)$ with JQ1 across a range of doses (Fig. 5C). To determine whether and how the combination of the two drugs may affect cell cycle, we examined cell cycle distribution under single or combinations of drug treatment using EdU labeling. While a small percentage of cells was still able to incorporate EdU and progress though the cell cycle with treatment by single agents, cotreatment of palbociclib and JQ1 induced complete cell cycle arrest and abolishment of EdU incorporation in both NMC797 and NMC1015 cells (Fig. 5D). Consistent with this, cotreatment of palbociclib and JQ1 profoundly reduced the levels of E2F1 and its downstream target, cyclin A (Fig. 5E), which accumulates in S phase and is necessary for initiation and completion of DNA replication. Cotreatment of palbociclib and JQ1 did not induce cell death through mechanisms such as apoptosis, necroptosis, or autophagic cell death, marked by cleavedPARP (c-PARP) and Caspase-Glo $3 / 7$ assay (data not shown), phosphorylation of RIP1 (p-RIP1), or LC3-II/ LC3-I ratio, respectively (Fig. 5E), suggesting that the profound cell viability reduction induced by the combination treatment in vitro was primarily due to cell cycle arrest.

\section{The CDK4/6 inhibitor synergizes with JQ1 on NMC in vivo}

To validate the effectiveness of the combination therapy on NMC in vivo, we used a xenograft mouse model. Tumors generated from NMC1015 cells were established, and once they reached $200-300 \mathrm{~mm}^{3}$, mice were randomized into one of the four following treatment groups and treated for $21 \mathrm{~d}$ using well-established preclinical doses and regimens: (1) vehicle, (2) JQ1 alone, (3) palbociclib alone, and (4) JQ1 plus palbociclib. Despite a small initial weight loss seen in the palbociclib and combination treatment groups, the weight of mice of both groups recovered to the start point by the end of treatment, and no other signs of toxicity were observed (Supplemental Fig. S2A). A spider plot of tumor growth is shown in Figure 6A. The tumors in the vehicle group grew rapidly to the maximum size threshold within $8 \mathrm{~d}$, recapitulating the aggressive nature of NMC in human patients. While single treatment of JQ1 or palbociclib caused no tumor shrinkage and only slowed tumor growth, cotreatment of JQ1 and palbociclib caused tumor regression in the majority of tumors, and tumor size remained stable throughout the course of treatment. In only $8 \mathrm{~d}$, when tumor size necessitated the sacrifice of vehicle-treated mice, the drug combination therapy exerted substantial effects on every tumor and induced frank regression in five out of seven tumors up to $45.1 \%$ (Fig. 6B,C). During the course of treatment $(21 \mathrm{~d})$, all animals treated with vehicle or single agents had to be euthanized with the exception of one in the palbociclibalone group; however, no animals died in the presence of the combination (Fig. 6D). Even when drug treatment ceased, this drug combination significantly improved the median survival of the mice over each agent or vehicle alone (combination: $34 \mathrm{~d}$; palbociclib: $16 \mathrm{~d}$; JQ1: $12 \mathrm{~d}$; vehicle: 8 d) (Fig. 6D). Finally, as seen in vitro, palbociclib and JQ1 cotreatment profoundly reduced the expression of the cell growth marker Ki-67 and the levels of E2F1 and its downstream target, cyclin A, in vivo as measured by immunohistochemical staining and immunoblot analysis, respectively (Fig. 6E,F), suggesting that these agents induce a more complete cell cycle arrest compared with each agent alone. To investigate whether the tumor shrinkage induced by the combination treatment in vivo 
A

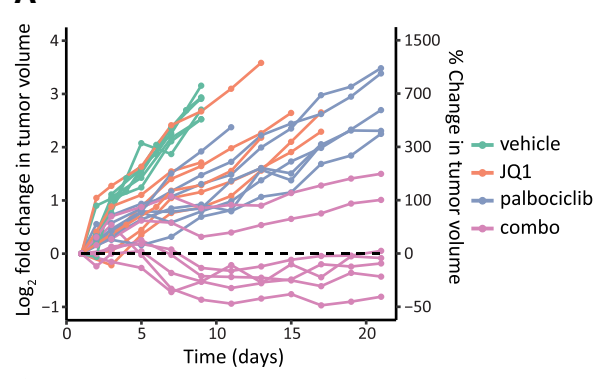

B

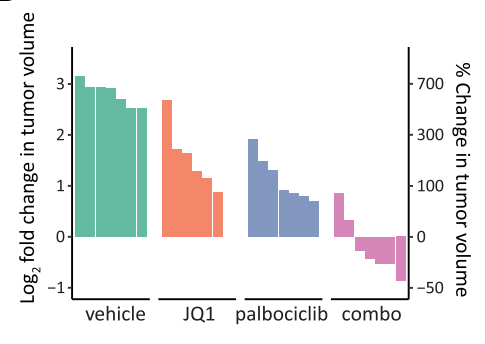

C

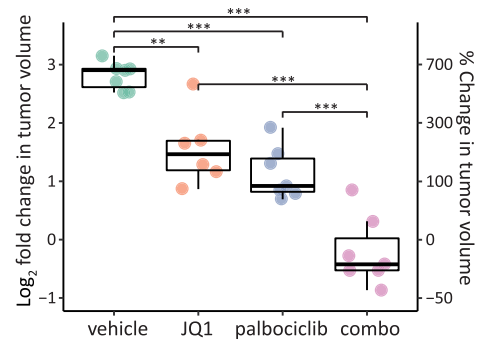

D
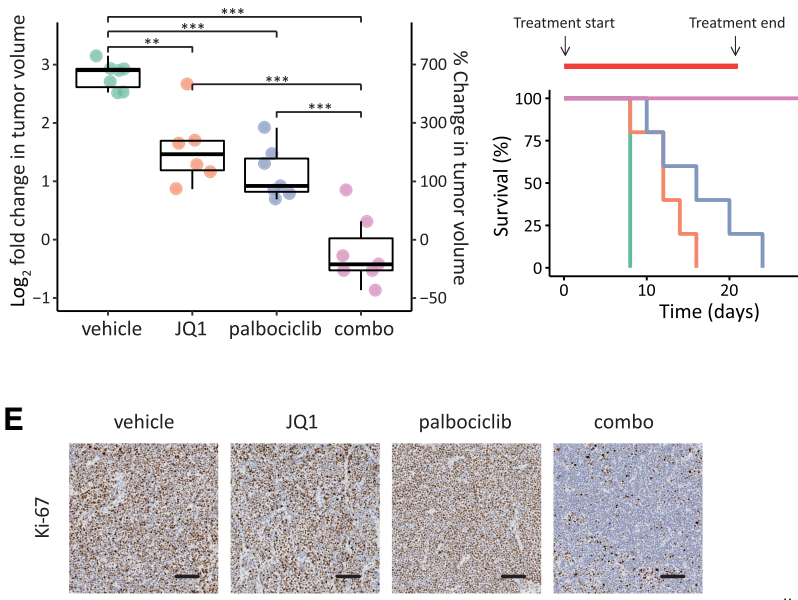

JQ1
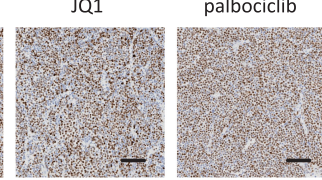

$\mathbf{F}$

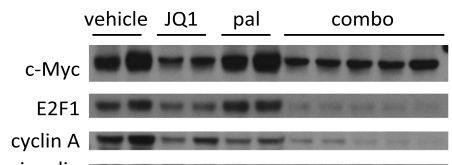

vinculin
G

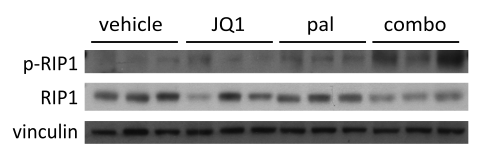

Figure 6. CDK4/6 inhibitor synergizes with JQ1 to inhibit NMC growth in vivo. $(A)$ NMC1015 cells were injected subcutaneously into nude mice (one to two tumors per mouse). Mice were randomized into the following four groups and treated with either vehicle $\left(n_{\text {mouse }}=\right.$ $4 ; n_{\text {tumor }}=7$ ), $45 \mathrm{mg} / \mathrm{kg} \mathrm{JQ1}$ (intraperitoneal injection; $\left.n_{\text {mouse }}=5 ; n_{\text {tumor }}=6\right), 100 \mathrm{mg} / \mathrm{kg}$ palbociclib (oral gavage; $n_{\text {mouse }}=5 ; n_{\text {tumor }}=7$ ), or a combination of the two drugs $\left(n_{\text {mouse }}=5\right.$; $\left.n_{\text {tumor }}=7\right)$ for $21 \mathrm{~d}$. The spider plot depicts tumor growth. Each line represents an individual tumor. The left axis indicates the $\log _{2}$ fold change in tumor volume, and the right axis indicates the percentage in tumor volume relative to day 0 (the day of enrollment). $(B, C)$ Waterfall plot and box plot depicting changes in tumor volume after $8 \mathrm{~d}$ of treatment with single or combined agents as indicated. Each bar or dot represents an individual tumor. $\left(^{* *}\right)$ $P<0.01 ;\left(^{* * *}\right) P<0.001$. (D) Survival of the mice is represented by a Kaplan-Meier plot. The duration of treatment is indicated at the top, and median survival per group is indicated at the right. Animals were euthanized when the tumor volume reached $1200 \mathrm{~mm}^{3}$. For mice bearing two tumors, the fast-growing one was considered. $\left(^{* *}\right) P<0.01$. (E) As in $A$. Mice were treated with the indicated drugs for $8 \mathrm{~d}$. Tumors were harvested $1 \mathrm{~h}$ after the last treatment and subjected to immunohistochemical staining for Ki-67 (brown). One representative image for each group is shown. Bars, $100 \mu \mathrm{m}$. Ki-67-positive cells were quantified using eSlide Manager. Data are the means \pm SD. $n=2 .\left(^{*}\right) P<0.05$, one-sided Student's $t$ test. $(F)$ As in $E$. Tumors were subjected to immunoblot analysis using the indicated antibodies. Each sample came from an individual tumor. (Pal) Palbociclib. (G) As in $A$. Mice were treated with the indicated drugs for $3 \mathrm{~d}$. Tumors were harvested $1 \mathrm{~h}$ after the last treatment and subjected to immunoblot analysis using the indicated antibodies. Each sample came from an individual tumor. (Pal) Palbociclib.

was due to apoptosis, we examined the c-PARP and cleaved caspase substrate levels in different treatment groups. Surprisingly, there was more apoptosis in the vehicle-treated tumors (Supplemental Fig. S2B). Such increased proliferation along with an increased apoptotic rate has been observed in other cancer types (Liu et al. 2001). However, compared with each agent alone, palbociclib and JQ1 cotreatment significantly increased the levels of p-RIP1 (Fig. 6G), suggesting the tumor shrinkage induced by the combination treatment in vivo was due to increased necroptosis.

\section{Discussion}

NMC is a particularly lethal cancer that does not benefit from conventional chemotherapy and has an overall survival of only 6.9 mo (French et al. 2008; Bauer et al. 2012). Thus, it represents a model disease for the clinical testing of BETis given the direct oncogenic driver role that BRD4-NUT plays in NMC and the urgent need for novel therapeutic approaches. Despite the promising re- sponses seen in some patients treated with BETis, why most patients fail to respond or why even the responders eventually relapse is unknown. Understanding which signaling pathways can modulate the sensitivity of NMC tumors to BETis could inform new therapeutic approaches to treat this deadly cancer. Here, using high-throughput loss-of-function and gain-of-function screening technologies, we systematically explored $\sim 900$ known drivers of tumorigenesis for their ability to impact NMC's response to BETis with the hope that some of these pathways might contribute to NMC tumorigenesis in a basal state and that inhibiting these pathways might improve the efficacy of BETi therapy. We identified multiple cancer driver networks that can genetically modify BRD4-NUT dependency to partially compensate for it and drive proliferation and survival of NMC cancer cells during BETi treatment. Unlike the MYC locus, the regulatory regions and gene bodies of those cancer drivers do not fall in BRD4-NUT megadomains (Supplemental Fig. S3A), suggesting that those cancer drivers are not the direct targets of BRD4-NUT in this disease and compensate for BRD4NUT inhibition in an indirect manner. Overall, those 
cancer drivers that we identified largely fall into six categories (Fig. 7).

The first category encompasses MYC and MYC-related genes such as MYCN, encoding N-Myc. Structurally, the coding regions of both $M Y C$ and $M Y C N$ are highly homologous. Both c-Myc and N-Myc form heterodimers with Max at consensus E-box sequences (CANNTG) and regulate transcription. Functionally, c-Myc and N-Myc are partially redundant but have several distinct spatiotemporal expression patterns and functions (Rickman et al. 2018). In addition to the previously validated MYC gene, we recovered wild-type MYCN and a mutant form: $M Y C N$ (c.131C > T; p.P44L). The N-Myc ${ }^{\mathrm{P} 44 \mathrm{~L}}$ mutation is recurrently identified in different cancers but remains to be characterized biochemically (Rickman et al. 2018). Our results suggested that $\mathrm{N}-\mathrm{Myc}^{\mathrm{P} 44 \mathrm{~L}}$ is indeed an activating mutation given its stronger phenotype (i.e., greater fold change) than wild-type N-Myc in our screen. The fact that many of the mutant alleles picked up by TUSON Explorer achieved stronger phenotypes than their corresponding wild-type alleles in our oncogene screen (Supplemental Table S1) confirmed the robustness of the TUSON Explorer algorithm to identify bona fide activating oncogenic mutations from passenger mutations. We also recovered a mutant form of $M A X$ (c.179G > A; p.R60Q) in our oncogene screen. The $\mathrm{Max}^{\mathrm{R} 60 \mathrm{Q}}$ mutation is recurrently identified in many cancers and is suggested to be an activating mutation through inhibition of Max homodimerization but not disruption of c-Myc/Max heterodimerization, thus shifting the balance toward c-Myc activation in proliferating cells (Dela Cruz et al. 2016). We also recovered the tumor suppressor FBXW7-the Fbox substrate adaptor component of the $\mathrm{SCF}^{\mathrm{Fbx} 7} \mathrm{E} 3$ ubiquitin ligase that targets c-Myc for degradation (Welcker et al. 2004; Yada et al. 2004) —in our loss-of-function screen. Together, our data confirmed the central role of c-Myc signaling in mediating the oncogenic function of BRD4-NUT and revealed that there are many potential ways for NMC cancer cells to sustain MYC function, thus bypassing the need for BRD4-NUT during BRD4 inhibition.

The second class of genes encompasses the RTK signaling pathway. We recovered ERBB2, SRC, PIK3CA (c.3140A > G; p.H1047R), and several RAS-related genes, including wild-type $R R A S 2$, mutant $R R A S 2$ (c.216A > C; p.Q72H), and wild-type $H$-RAS, in our oncogene screen as well as their negative regulator, NF1 (Ohba et al.

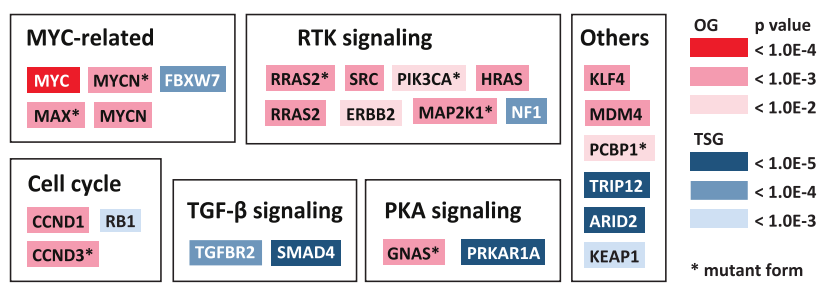

Figure 7. Summary of the cancer drivers and genetic pathways uncovered in this study. Top hits of the CRISPR and ORF screens (FDR $<0.05$ ) are grouped based on the cell signaling pathways to which they belong.
2000), in the TSG screen. We further showed that the RRAS2 ${ }^{\mathrm{Q} 72 \mathrm{H}}$ mutant mediates JQ1 resistance predominately through ERK signaling. The importance of ERK signaling was further supported by the fact that the upstream kinase of ERK1/2, MAP2K1, with an activating mutation (c.371C > A; p.P124Q) that harbors RAF-independent kinase activity (Carlino et al. 2015) scored highly in our screen. Previous work has demonstrated that a mechanism of resistance to BETis in ovarian cancers involves the activation of RTKs and their downstream signaling pathways (Kurimchak et al. 2016). Our results suggest that activation of RTK signaling can mediate BETi resistance in NMC cancer cells as well.

The third general class of suppressors involves the GPCR/cAMP/PKA signaling pathway. We identified GNAS (c.2530C > T; p.R844C) in our oncogene screen. GNAS encodes the a subunit of the stimulatory $\mathrm{G}$ protein that transduces signals from GPCR signaling to the cAMP/PKA pathway. Activating mutations in GNAS promotes tumorigenesis through activation of PKA, resulting in up-regulation of Wnt and MAPK/ERK signaling (Wilson et al. 2010; Regard et al. 2011; Nomura et al. 2014). In agreement with the gain-of-function screen, a negative regulator of PKA, PRKAR1A, was one of the top-scoring TSGs recovered in our loss-of-function screen. PRKAR1A encodes the type 1a regulatory subunit (RIa) of PKA. Lossof-function mutations of PRKAR1A are responsible for the Carney complex (CNC) (Bertherat et al. 2009; Horvath et al. 2010), a multiple neoplasia syndrome. Its inactivation acts as a tumorigenic signal through increasing PKA activity, resulting in ERK signaling activation, Wnt signaling activation, c-Myc activation, up-regulation of D-type cyclins and E2F1, increased cell cycle rates, and decreased apoptosis (Robinson-White et al. 2003, 2006a,b; Nadella and Kirschner 2005; Nesterova et al. 2008; Almeida et al. 2010; Basso et al. 2014). Given the important role that ERK signaling and cell cycle entry play in BETi resistance in our screens, their up-regulation through increased PKA activity could be a plausible mechanism of GNAS and PRKAR1A loss-mediated BETi resistance in NMC and is worthy of further investigation.

The fourth class involves the TGF- $\beta$ pathway. The TGF$\beta$ pathway is known to play both anti-tumorigenic and protumorigenic roles in cancer biology, depending on the tumor type, stage, genetic background, and microenvironment as well as the status of Smad and other pathways (Inman 2011). Up-regulation of TGF- $\beta$ signaling has been proposed as a mechanism of BETi resistance in colon cancer cells (Shi et al. 2016). However, we found that loss of $S M A D 4$ or, with slightly less potency, TGFBR2, two major components of the canonical TGF- $\beta$ signaling pathway, mediates BETi resistance in NMC in our screen. We also found that the TGF- $\beta$ signaling is one of the top signaling pathways transcriptionally induced by JQ1 treatment in NMC1015 cells (Supplemental Fig. S4A). Thus, it is likely that activation of TGF- $\beta$ signaling could mediate part of the anti-cancer effect of BETis on NMC.

A fifth class is a catchall category of several unrelated drivers such as the Yamanaka factor KLF4, MDM4, and PCBP1 (c.299T > C; p.L100P) in the oncogene screen and 
TRIP12, ARID2, and KEAP1 in the TSG screen. Of these, we characterized the mechanism of KLF4-mediated JQ1 resistance. We found that KLF4- expressing cells are able to sustain the E2F and c-Myc transcription program during BETi treatment. Given the central role that MYC plays in mediating the oncogenic function of the BRD4-NUT fusion protein, it is not surprising that KLF4 and other modifiers of BETi treatment might regulate MYC function. Whether and how the other novel hits recovered in our screens impact MYC function are worthy of future investigation.

The final class of suppressors involves cell cycle regulation. Our data revealed the central role of cell cycle regulators in mediating the oncogenic function of BRD4-NUT and demonstrated that there are multiple ways for NMC cancer cells to bypass the cell cycle arrest induced by BETis-through RB1 loss or up-regulation of D-type cyclins. This suggested that reinforcing cell cycle arrest might improve the efficacy of BETis. Critically, we showed that CDK4/6 inhibition synergizes with BETis against NMC tumors in vitro and in vivo. Importantly, CDK4/6 inhibitors such as palbociclib, ribociclib, and abemaciclib have been approved in clinics for the treatment of certain breast cancers. Therefore, the pharmacokinetic and pharmacodynamic profiles of the relevant drugs have been established. Our results on synergy and the favorable clinical properties of the relevant inhibitors of these pathways suggest that this combination forms the basis of a clinical trial for combination therapy of BETis and CDK4/6 inhibitors on NMC.

In summary, analysis of cancer drivers' effects on BRD4-NUT dependency in NMC has provided a broad picture of the genetic landscape of resistance to BETis in this cancer. These pathways now become candidates to explore in NMC tumors that evolve BETi resistance during therapy. In addition, beyond the synergism that we identified with CDK4/6 inhibitors, future therapies that reinforce other aspects of the mechanism of BETi inhibition of tumorigenesis might also show activity in combination therapy to further improve the efficacy of BETis.

\section{Materials and methods}

Cell culture and reagents

NMC1015 and NMC797 cells were kindly provided by Dr. Christopher A. French (Brigham and Women's Hospital and Harvard Medical School). 293T cells were purchased from American Type Culture Collection. NMC1015, NMC797, and 293T cells were maintained in DMEM-Glutamax (Thermo Fisher Scientific) supplemented with $10 \%$ heat-inactivated fetal bovine serum /GE Healthcare HyClone), $100 \mathrm{IU} / \mathrm{mL}$ penicillin, and $100 \mu \mathrm{g} / \mathrm{mL}$ streptomycin in a humidified atmosphere of $95 \%$ air and $5 \%$ $\mathrm{CO}_{2}$ at $37^{\circ} \mathrm{C}$. SCH772984 and GDC-0068 were purchased from Selleck Chemicals. JQ1 used in vitro was purchased from Sigma-Aldrich, and JQ1 used in vivo was a gift from Dr. Jun Qi (Dana-Farber Cancer Institute and Harvard Medical School).

Plasmids, cloning, and viral transduction

gRNAs were cloned into pLentiCRISPR V2 (Addgene plasmid 52961) as described previously (Sanjana et al. 2014).
The sequences targeted by the gRNAs used were GFP /GGGCG AGGAGCTGTTCACCG), AAVS1 (GGGGCCACTAGGGACA GGAT), RB1 gRNA1 (GGTTCTTTGAGCAACATGGG), and RB1 gRNA2 (GCAGTGTGATTATTCTGGAG).

cDNAs were picked from the ORFeome version 8.1 or Ultimate ORF libraries. Stop codons and mutations were introduced using the QuikChange II XL site-directed mutagenesis kit (Agilent Technologies). cDNAs were subcloned into the pHAGE-TRExBC-DEST vector via LR recombinase reaction (Invitrogen).

To produce lentiviruses, $293 \mathrm{~T}$ cells were transfected with vector DNA, pRev, pTat, pHIV Gag/pol, and pVSVG. Viruses were harvested $48 \mathrm{~h}$ after transfection and filtered $(45-\mu \mathrm{m}$ pore size). TransIT-293 (Mirus) was used to transfect 293 T cells.

Cells were transduced with $4 \mu \mathrm{g} / \mathrm{mL}$ polybrene (Sigma), and infected cells were selected using $1 \mu \mathrm{g} / \mathrm{mL}$ puromycin (Clontech) for $3 \mathrm{~d}$. pLentiCRISPR-V2-infected cells were subjected to cell viability assay or immunoblot analysis $1 \mathrm{wk}$ after infection to allow for genome modification by Cas9. Cells expressing ORFs were treated with $1 \mu \mathrm{g} / \mathrm{mL}$ Dox for $3 \mathrm{~d}$ prior to subsequent experiments for ORF expression and maintained in medium containing $1 \mu \mathrm{g} /$ $\mathrm{mL}$ Dox during subsequent experiments.

\section{Western blot analysis}

The Western blot method is described in detail in the Supplemental Material. The following antibodies were from Cell Signaling: GAPDH (8884), phospho-ERK1/2 (T202/Y204; 4370P), total ERK1/2 (4695P), phospho-AKT (S473; 4060P), total AKT (2920S), phospho-p90RSK (Ser380; 9341S), c-Myc (5605S), cyclin D1 (2978S), phospho-PRAS40 (Thr246; 2997S), KLF4 (4038S), phospho-Rb (Ser780; 3590S), total Rb (9309S), E2F1 (3742S), c-PARP (9541S), cleaved caspase substrate motif (8698S), phospho-RIP1 (Ser166; 65746S), total RIP1 (3493T), and LC3B (3868T). Other antibodies used were cyclin A (Santa Cruz Biotechonology, sc-751), vinculin (Sigma, V9131), and RRAS2 (Abcam, ab182264).

\section{Colony formation assay}

Single-cell suspensions were seeded into six-well plates $(200$ cells per well) and incubated overnight before continuous treatment of DMSO or $200 \mathrm{nM} \mathrm{JQ} 1$ for the indicated times, with drug and medium replaced every $3 \mathrm{~d}$. At the end of treatment, cells were fixed with $10 \%$ trichloroacetic acid, washed, and stained with methylene blue (Sigma-Aldrich). Colony numbers of each condition were quantified using Image J and normalized to control cells under DMSO treatment.

Cell viability assay

The effects of drugs on cell viability were determined by SRB (Sigma-Aldrich) as described previously (Vichai and Kirtikara 2006).

\section{Cell cycle analysis}

Cells seeded in six-well plates $\left(5 \times 10^{4}\right.$ cells per well) were treated with DMSO or $200 \mathrm{nM}$ JQ1 for $48 \mathrm{~h}$. Cells were pulsed with $10 \mu \mathrm{M}$ EdU final concentration for $1 \mathrm{~h}$ using the Click-iT Plus EdU Alexa fluor 647 flow cytometry assay kit (Thermo Fisher Scientific) and then processed according to the manufacturer's instructions. Samples were analyzed by flow cytometry (BD LSR II).

$R T-q P C R$

Total RNA was isolated using the RNAeasy minikit (Qiagen), and cDNA was synthesized using SuperScript IV (Invitrogen) 
according to manufacturer's instructions. RT-qPCR was performed in triplicate using the TaqMan gene expression master mix (Invitrogen) with TaqMan gene expression assay (Life Technologies) on an Applied Biosystems Fast 7500 machine using GAPDH as the endogenous normalization control. The IDs for the TaqMan assays used were as follows: GAPDH (Hs99999 905_m1), MYC (Hs00153408_m1), CCAT1 (Hs04402620_m1), and CASC19 (Hs04405851_g1).

\section{Gene expression profiling}

NMC1015 cells were transduced with pHAGE-TREx-KLF4 or empty vector. Infected cells were selected using $1 \mu \mathrm{g} / \mathrm{mL}$ puromy$\operatorname{cin}$ (Clontech) for $3 \mathrm{~d}$. Cells were then passaged for $1 \mathrm{wk}$ and treated with $1 \mu \mathrm{g} / \mathrm{mL}$ Dox (Clontech) for $3 \mathrm{~d}$ to allow for gene expression. Cells were then treated with $200 \mathrm{nM} \mathrm{JQ1}$ in medium containing $1 \mu \mathrm{g} / \mathrm{mL}$ Dox for $0 \mathrm{~h}, 6 \mathrm{~h}, 24 \mathrm{~h}$ or $7 \mathrm{~d}$ (two replicates for each condition). Total RNA was isolated using the RNAeasy minikit (Qiagen). RNA-seq libraries were generated using NEBNext Ultra RNA library preparation kit (New England Biolabs). Fiftybase-pair single-end sequencing was performed using an Illumina NextSeq. Reads were aligned to the hg19 genome using HiSat2 (Pertea et al. 2016); transcripts and frequencies were assessed from the aligned data by subread (Liao et al. 2013), and edgeR (Robinson et al. 2010) was used to identify DEGs and generate the signed LR scores used for GSEA (http://www.broadinstitute. org/gsea; Subramanian et al. 2005).

\section{Xenograft mouse model}

The xenograft mouse model is described in the Supplemental Material.

\section{Statistical analysis}

Data are presented as the mean $\pm S D$, and significance was analyzed using the two-sided Student's $t$-test unless specified otherwise. Differences were considered significant when $P<0.05$.

\section{Acknowledgments}

We thank M. Brown, C. French, and A. Toker for advice and reagents. This work was supported with funding from the Ludwig Foundation and a National Institutes of Health grant (R01CA111754) to K.C. S.J.E. is an Investigator with the Howard Hughes Medical Institute.

Author contributions: S.L. and S.J.E. developed the concept and wrote the manuscript. S.L. designed and performed experiments and analyzed the data, and S.J.E. supervised the study. O.M. and K.C. provided expertise in xenograft mouse models.

\section{References}

Alekseyenko AA, Walsh EM, Wang X, Grayson AR, Hsi PT, Kharchenko PV, Kuroda MI, French CA. 2015. The oncogenic BRD4-NUT chromatin regulator drives aberrant transcription within large topological domains. Genes Dev 29: 1507-1523.

Almeida MQ, Muchow M, Boikos S, Bauer AJ, Griffin KJ, Tsang KM, Cheadle C, Watkins T, Wen F, Starost MF, et al. 2010. Mouse Prkarla haploinsufficiency leads to an increase in tumors in the Trp $53^{+/-}$or $\mathrm{Rb}^{+/-}$backgrounds and chemically induced skin papillomas by dysregulation of the cell cycle and Wnt signaling. Hum Mol Genet 19: 1387-1398.
Basso F, Rocchetti F, Rodriguez S, Nesterova M, Cormier F, Stratakis CA, Ragazzon B, Bertherat J, Rizk-Rabin M. 2014. Comparison of the effects of PRKAR1A and PRKAR2B depletion on signaling pathways, cell growth, and cell cycle control of adrenocortical cells. Horm Metab Res 46: 883-888.

Bauer DE, Mitchell CM, Strait KM, Lathan CS, Stelow EB, Luer SC, Muhammed S, Evans AG, Sholl LM, Rosai J, et al. 2012. Clinicopathologic features and long-term outcomes of NUT midline carcinoma. Clin Cancer Res 18: 5773-5779.

Bertherat J, Horvath A, Groussin L, Grabar S, Boikos S, Cazabat L, Libe R, Rene-Corail F, Stergiopoulos S, Bourdeau I, et al. 2009. Mutations in regulatory subunit type $1 \mathrm{~A}$ of cyclic adenosine 5'-monophosphate-dependent protein kinase (PRKAR1A): phenotype analysis in 353 patients and 80 different genotypes. J Clin Endocrinol Metab 94: 2085-2091.

Carlino MS, Fung C, Shahheydari H, Todd JR, Boyd SC, Irvine M, Nagrial AM, Scolyer RA, Kefford RF, Long GV, et al. 2015. Preexisting MEK1P124 mutations diminish response to BRAF inhibitors in metastatic melanoma patients. Clin Cancer Res 21: 98-105.

Chan AM, Miki T, Meyers KA, Aaronson SA. 1994. A human oncogene of the RAS superfamily unmasked by expression cDNA cloning. Proc Nat1 Acad Sci 91: 7558-7562.

Chou TC, Talalay P. 1984. Quantitative analysis of dose-effect relationships: the combined effects of multiple drugs or enzyme inhibitors. Adv Enzyme Regul 22: 27-55.

Davoli T, Xu AW, Mengwasser KE, Sack LM, Yoon JC, Park PJ, Elledge SJ. 2013. Cumulative haploinsufficiency and triplosensitivity drive aneuploidy patterns and shape the cancer genome. Cell 155: 948-962.

Dela Cruz FS, Diolaiti D, Turk AT, Rainey AR, Ambesi-Impiombato A, Andrews SI, Mansukhani MM, Nagy PL, Alvarez MJ, Califano A, et al. 2016. A case study of an integrative genomic and experimental therapeutic approach for rare tumors: identification of vulnerabilities in a pediatric poorly differentiated carcinoma. Genome Med 8: 116.

De Raedt T, Beert E, Pasmant E, Luscan A, Brems H, Ortonne N, Helin K, Hornick JL, Mautner V, Kehrer-Sawatzki H, et al. 2014. PRC2 loss amplifies Ras-driven transcription and confers sensitivity to BRD4-based therapies. Nature 514: $247-251$.

Dyson NJ. 2016. RB1: a prototype tumor suppressor and an enigma. Genes Dev 30: 1492-1502.

Farrugia MK, Sharma SB, Lin CC, McLaughlin SL, Vanderbilt DB, Ammer AG, Salkeni MA, Stoilov P, Agazie YM, Creighton CJ, et al. 2015. Regulation of anti-apoptotic signaling by Kruppellike factors 4 and 5 mediates lapatinib resistance in breast cancer. Cell Death Dis 6: e1699.

Fong CY, Gilan O, Lam EY, Rubin AF, Ftouni S, Tyler D, Stanley K, Sinha D, Yeh P, Morison J, et al. 2015. BET inhibitor resistance emerges from leukaemia stem cells. Nature 525: 538-542.

French CA, Miyoshi I, Kubonishi I, Grier HE, Perez-Atayde AR, Fletcher JA. 2003. BRD4-NUT fusion oncogene: a novel mechanism in aggressive carcinoma. Cancer Res 63: 304-307.

French CA, Ramirez CL, Kolmakova J, Hickman TT, Cameron MJ, Thyne ME, Kutok JL, Toretsky JA, Tadavarthy AK, Kees UR, et al. 2008. BRD-NUT oncoproteins: a family of closely related nuclear proteins that block epithelial differentiation and maintain the growth of carcinoma cells. Oncogene 27: 2237-2242.

Futreal PA, Coin L, Marshall M, Down T, Hubbard T, Wooster R, Rahman N, Stratton MR. 2004. A census of human cancer genes. Nat Rev Cancer 4: 177-183. 
Graham SM, Cox AD, Drivas G, Rush MG, D'Eustachio P, Der CJ. 1994. Aberrant function of the Ras-related protein TC21/ R-Ras2 triggers malignant transformation. Mol Cell Biol 14: 4108-4115.

Grayson AR, Walsh EM, Cameron MJ, Godec J, Ashworth T, Ambrose JM, Aserlind AB, Wang H, Evan G, Kluk MJ, et al. 2014. MYC, a downstream target of BRD-NUT, is necessary and sufficient for the blockade of differentiation in NUT midline carcinoma. Oncogene 33: 1736-1742.

Harbinski F, Craig VI, Sanghavi S, Jeffery D, Liu L, Sheppard KA, Wagner S, Stamm C, Buness A, Chatenay-Rivauday C, et al. 2012. Rescue screens with secreted proteins reveal compensatory potential of receptor tyrosine kinases in driving cancer growth. Cancer Discov 2: 948-959.

Hogg SJ, Newbold A, Vervoort SJ, Cluse LA, Martin BP, Gregory GP, Lefebure M, Vidacs E, Tothill RW, Bradner JE, et al. 2016. BET inhibition induces apoptosis in aggressive B-cell lymphoma via epigenetic regulation of BCL-2 family members. Mol Cancer Ther 15: 2030-2041.

Horvath A, Bertherat J, Groussin L, Guillaud-Bataille M, Tsang K, Cazabat L, Libe R, Remmers E, Rene-Corail F, Faucz FR, et al. 2010. Mutations and polymorphisms in the gene encoding regulatory subunit type 1- $\alpha$ of protein kinase A (PRKAR1A): an update. Hum Mutat 31: 369-379.

Hunter JC, Manandhar A, Carrasco MA, Gurbani D, Gondi S, Westover KD. 2015. Biochemical and structural analysis of common cancer-associated KRAS mutations. Mol Cancer Res 13: 1325-1335.

Inman GJ. 2011. Switching TGF $\beta$ from a tumor suppressor to a tumor promoter. Curr Opin Genet Dev 21: 93-99.

Jang JE, Eom JI, Jeung HK, Cheong JW, Lee JY, Kim JS, Min YH. 2017. AMPK-ULK1-mediated autophagy confers resistance to BET inhibitor JQ1 in acute myeloid leukemia stem cells. Clin Cancer Res 23: 2781-2794.

Janouskova H, El Tekle G, Bellini E, Udeshi ND, Rinaldi A, U1bricht A, Bernasocchi T, Civenni G, Losa M, Svinkina T, et al. 2017. Opposing effects of cancer-type-specific SPOP mutants on BET protein degradation and sensitivity to BET inhibitors. Nat Med 23: 1046-1054.

Koepp DM, Schaefer LK, Ye X, Keyomarsi K, Chu C, Harper JW, Elledge SJ. 2001. Phosphorylation-dependent ubiquitination of cyclin E by the SCFFbw7 ubiquitin ligase. Science 294: 173-177.

Kumar K, Raza SS, Knab LM, Chow CR, Kwok B, Bentrem DI, Popovic R, Ebine K, Licht JD, Munshi HG. 2015. GLI2-dependent c-MYC upregulation mediates resistance of pancreatic cancer cells to the BET bromodomain inhibitor JQ1. Sci Rep 5: 9489.

Kurimchak AM, Shelton C, Duncan KE, Johnson KJ, Brown J, O'Brien S, Gabbasov R, Fink LS, Li Y, Lounsbury N, et al. 2016. Resistance to BET bromodomain inhibitors is mediated by kinome reprogramming in ovarian cancer. Cell Rep 16: 1273-1286.

Li W, Xu H, Xiao T, Cong L, Love MI, Zhang F, Irizarry RA, Liu JS, Brown M, Liu XS. 2014. MAGeCK enables robust identification of essential genes from genome-scale CRISPR/Cas9 knockout screens. Genome Biol 15: 554.

Liao Y, Smyth GK, Shi W. 2013. The subread aligner: fast, accurate and scalable read mapping by seed-and-vote. Nucleic Acids Res 41: e108.

Liao S, Davoli T, Leng Y, Li MZ, Xu Q, Elledge SJ. 2017. A genetic interaction analysis identifies cancer drivers that modify EGFR dependency. Genes Dev 31: 184-196.

Liu S, Edgerton SM, Moore DH II, Thor AD. 2001. Measures of cell turnover (proliferation and apoptosis) and their associa- tion with survival in breast cancer. Clin Cancer Res 7: 1716-1723.

Lund RJ, Huhtinen K, Salmi J, Rantala J, Nguyen EV, Moulder R, Goodlett DR, Lahesmaa R, Carpen O. 2017. DNA methylation and transcriptome changes associated with cisplatin resistance in ovarian cancer. Sci Rep 7: 1469.

Marcotte R, Sayad A, Brown KR, Sanchez-Garcia F, Reimand J, Haider M, Virtanen C, Bradner JE, Bader GD, Mills GB, et al. 2016. Functional genomic landscape of human breast cancer drivers, vulnerabilities, and resistance. Cell 164: 293-309.

McCleland ML, Mesh K, Lorenzana E, Chopra VS, Segal E, Watanabe C, Haley B, Mayba O, Yaylaoglu M, Gnad F, et al. 2016. CCAT1 is an enhancer-templated RNA that predicts BET sensitivity in colorectal cancer. J Clin Invest 126: 639-652.

Movilla N, Crespo P, Bustelo XR. 1999. Signal transduction elements of TC21, an oncogenic member of the R-Ras subfamily of GTP-binding proteins. Oncogene 18: 5860-5869.

Murphy GA, Graham SM, Morita S, Reks SE, Rogers-Graham K, Voitek A, Kelley GG, Der CJ. 2002. Involvement of phosphatidylinositol 3-kinase, but not RalGDS, in TC21/R-Ras2-mediated transformation. J Biol Chem 277: 9966-9975.

Nadella KS, Kirschner LS. 2005. Disruption of protein kinase a regulation causes immortalization and dysregulation of $\mathrm{D}$ type cyclins. Cancer Res 65: 10307-10315.

Nesterova M, Bossis I, Wen F, Horvath A, Matyakhina L, Stratakis CA. 2008. An immortalized human cell line bearing a PRKAR1A-inactivating mutation: effects of overexpression of the wild-type allele and other protein kinase A subunits. I Clin Endocrinol Metab 93: 565-571.

Nomura R, Saito T, Mitomi H, Hidaka Y, Lee SY, Watanabe S, Yao T. 2014. GNAS mutation as an alternative mechanism of activation of the Wnt/ $\beta$-catenin signaling pathway in gastric adenocarcinoma of the fundic gland type. Hum Pathol 45: 2488-2496.

Ohba Y, Mochizuki N, Yamashita S, Chan AM, Schrader JW, Hattori S, Nagashima K, Matsuda M. 2000. Regulatory proteins of R-Ras, TC21/R-Ras2, and M-Ras/R-Ras3. I Biol Chem 275: 20020-20026.

Pavlova NN, Pallasch C, Elia AE, Braun CJ, Westbrook TF, Hemann M, Elledge SJ. 2013. A role for PVRL4-driven cellcell interactions in tumorigenesis. Elife 2: e00358.

Pertea M, Kim D, Pertea GM, Leek JT, Salzberg SL. 2016. Transcript-level expression analysis of RNA-seq experiments with HISAT, StringTie and Ballgown. Nat Protoc 11: 1650-1667.

Polo JM, Anderssen E, Walsh RM, Schwarz BA, Nefzger CM, Lim SM, Borkent M, Apostolou E, Alaei S, Cloutier J, et al. 2012. A molecular roadmap of reprogramming somatic cells into iPS cells. Cell 151: 1617-1632.

Regard JB, Cherman N, Palmer D, Kuznetsov SA, Celi FS, Guettier JM, Chen $M$, Bhattacharyya N, Wess J, Coughlin SR, et al. 2011. Wnt/ $\beta$-catenin signaling is differentially regulated by $\mathrm{G} \alpha$ proteins and contributes to fibrous dysplasia. Proc Nat1 Acad Sci 108: 20101-20106.

Rickman DS, Schulte JH, Eilers M. 2018. The expanding world of N-MYC-driven tumors. Cancer Discov 8: 150-163.

Robinson-White A, Hundley TR, Shiferaw M, Bertherat J, Sandrini F, Stratakis CA. 2003. Protein kinase-A activity in PRKAR1A-mutant cells, and regulation of mitogen-activated protein kinases ERK1/2. Hum Mol Genet 12: 1475-1484.

Robinson-White A, Meoli E, Stergiopoulos S, Horvath A, Boikos S, Bossis I, Stratakis CA. 2006a. PRKAR1A mutations and protein kinase A interactions with other signaling pathways in the adrenal cortex. J Clin Endocrinol Metab 91: 2380-2388. 
Robinson-White AJ, Leitner WW, Aleem E, Kaldis P, Bossis I, Stratakis CA. 2006b. PRKAR1A inactivation leads to increased proliferation and decreased apoptosis in human B lymphocytes. Cancer Res 66: 10603-10612.

Robinson MD, McCarthy DI, Smyth GK. 2010. edgeR: a Bioconductor package for differential expression analysis of digital gene expression data. Bioinformatics 26: 139-140.

Rosario M, Paterson HF, Marshall CJ. 2001. Activation of the Ral and phosphatidylinositol $3^{\prime}$ kinase signaling pathways by the ras-related protein TC21. Mol Cell Biol 21: 3750-3762.

Rowland BD, Peeper DS. 2006. KLF4, p21 and context-dependent opposing forces in cancer. Nat Rev Cancer 6: 11-23.

Sack LM, Davoli T, Li MZ, Li Y, Xu Q, Naxerova K, Wooten EC, Bernardi RJ, Martin TD, Chen T, et al. 2018. Profound tissue specificity in proliferation control underlies cancer drivers and aneuploidy patterns. Cell 173: 499-514 e423.

Sanjana NE, Shalem O, Zhang F. 2014. Improved vectors and genome-wide libraries for CRISPR screening. Nat Methods 11: 783-784.

Santarius T, Shipley J, Brewer D, Stratton MR, Cooper CS. 2010. A census of amplified and overexpressed human cancer genes. Nat Rev Cancer 10: 59-64.

Schmitz R, Young RM, Ceribelli M, Jhavar S, Xiao W, Zhang M, Wright G, Shaffer AL, Hodson DJ, Buras E, et al. 2012. Burkitt lymphoma pathogenesis and therapeutic targets from structural and functional genomics. Nature 490: 116-120.

Schulze A, Zerfass K, Spitkovsky D, Middendorp S, Berges J, Helin K, Jansen-Durr P, Henglein B. 1995. Cell cycle regulation of the cyclin A gene promoter is mediated by a variant E2F site. Proc Nat1 Acad Sci 92: 11264-11268.

Sharifnia T, Rusu V, Piccioni F, Bagul M, Imielinski M, Cherniack AD, Pedamallu CS, Wong B, Wilson FH, Garraway LA, et al. 2014. Genetic modifiers of EGFR dependence in non-small cell lung cancer. Proc Natl Acad Sci 111: 18661-18666.

Shi X, Mihaylova VT, Kuruvilla L, Chen F, Viviano S, Baldassarre M, Sperandio D, Martinez R, Yue P, Bates JG, et al. 2016. Loss of TRIM33 causes resistance to BET bromodomain inhibitors through MYC- and TGF- $\beta$-dependent mechanisms. Proc Natl Acad Sci 113: E4558-E4566.

Shu S, Lin CY, He HH, Witwicki RM, Tabassum DP, Roberts JM, Janiszewska M, Huh SJ, Liang Y, Ryan J, et al. 2016. Response and resistance to BET bromodomain inhibitors in triple-negative breast cancer. Nature 529: 413-417.

Stathis A, Bertoni F. 2018. BET proteins as targets for anticancer treatment. Cancer Discov 8: 24-36.
Stathis A, Zucca E, Bekradda M, Gomez-Roca C, Delord JP, de La Motte Rouge T, Uro-Coste E, de Braud F, Pelosi G, French CA. 2016. Clinical response of carcinomas harboring the BRD4NUT oncoprotein to the targeted bromodomain inhibitor OTX015/MK-8628. Cancer Discov 6: 492-500.

Subramanian A, Tamayo P, Mootha VK, Mukherjee S, Ebert BL, Gillette MA, Paulovich A, Pomeroy SL, Golub TR, Lander ES, et al. 2005. Gene set enrichment analysis: a knowledgebased approach for interpreting genome-wide expression profiles. Proc Natl Acad Sci 102: 15545-15550.

Taube JH, Herschkowitz JI, Komurov K, Zhou AY, Gupta S, Yang J, Hartwell K, Onder TT, Gupta PB, Evans KW, et al. 2010. Core epithelial-to-mesenchymal transition interactome gene-expression signature is associated with claudin-low and metaplastic breast cancer subtypes. Proc Natl Acad Sci 107: 15449-15454.

Toretsky JA, Jenson J, Sun CC, Eskenazi AE, Campbell A, Hunger SP, Caires A, Frantz C, Hill JL, Stamberg J. 2003. Translocation $(11 ; 15 ; 19)$ : a highly specific chromosome rearrangement associated with poorly differentiated thymic carcinoma in young patients. Am J Clin Oncol 26: 300-306.

Vichai V, Kirtikara K. 2006. Sulforhodamine B colorimetric assay for cytotoxicity screening. Nat Protoc 1: 1112-1116.

Welcker M, Orian A, Jin J, Grim JE, Harper JW, Eisenman RN, Clurman BE. 2004. The Fbw7 tumor suppressor regulates glycogen synthase kinase 3 phosphorylation-dependent c-Myc protein degradation. Proc Natl Acad Sci 101: 9085-9090.

Wilson CH, McIntyre RE, Arends MJ, Adams DJ. 2010. The activating mutation R201C in GNAS promotes intestinal tumourigenesis in $\mathrm{Apc}(\mathrm{Min} /+)$ mice through activation of Wnt and ERK1/2 MAPK pathways. Oncogene 29: 4567-4575.

Wilson TR, Fridlyand J, Yan Y, Penuel E, Burton L, Chan E, Peng J, Lin E, Wang Y, Sosman J, et al. 2012. Widespread potential for growth-factor-driven resistance to anticancer kinase inhibitors. Nature 487: 505-509.

Xiang JF, Yin QF, Chen T, Zhang Y, Zhang XO, Wu Z, Zhang S, Wang HB, Ge J, Lu X, et al. 2014. Human colorectal cancerspecific CCAT1-L IncRNA regulates long-range chromatin interactions at the MYC locus. Cell Res 24: 513-531.

Yada M, Hatakeyama S, Kamura T, Nishiyama M, Tsunematsu R, Imaki H, Ishida N, Okumura F, Nakayama K, Nakayama KI. 2004. Phosphorylation-dependent degradation of c-Myc is mediated by the F-box protein Fbw7. EMBO I 23: 2116 2125 . 


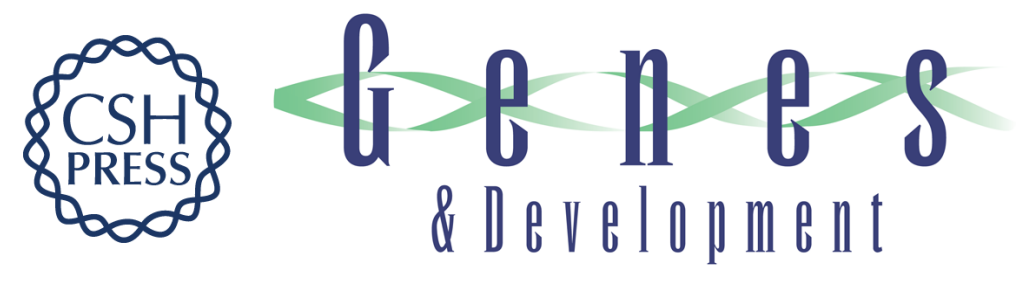

\section{Genetic modifiers of the BRD4-NUT dependency of NUT midline carcinoma uncovers a synergism between BETis and CDK4/6is}

Sida Liao, Ophélia Maertens, Karen Cichowski, et al.

Genes Dev. 2018, 32: originally published online August 22, 2018

Access the most recent version at doi:10.1101/gad.315648.118

\section{Supplemental http://genesdev.cshlp.org/content/suppl/2018/08/22/gad.315648.118.DC1 Material}

References This article cites 72 articles, 30 of which can be accessed free at:

http://genesdev.cshlp.org/content/32/17-18/1188.full.html\#ref-list-1

Creative This article is distributed exclusively by Cold Spring Harbor Laboratory Press for the first

Commons six months after the full-issue publication date (see

License http://genesdev.cshlp.org/site/misc/terms.xhtml). After six months, it is available under a Creative Commons License (Attribution-NonCommercial 4.0 International), as described at http://creativecommons.org/licenses/by-nc/4.0/.

Email Alerting Receive free email alerts when new articles cite this article - sign up in the box at the top Service right corner of the article or click here.

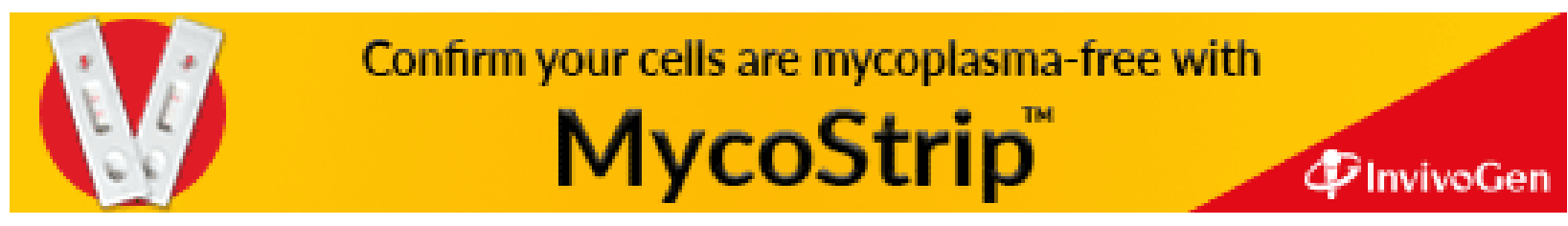

